
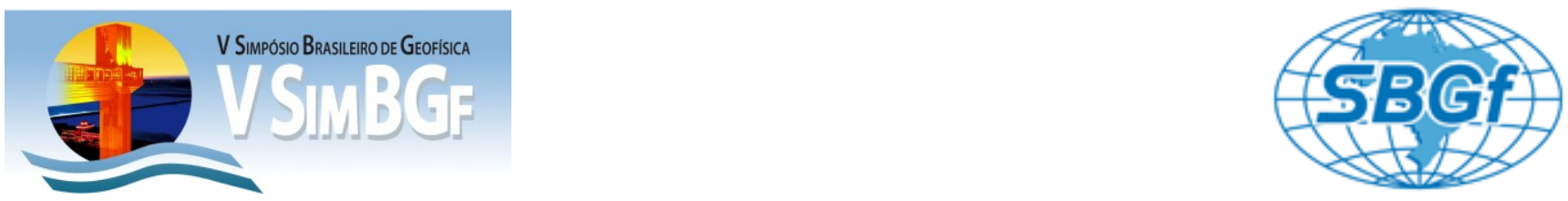

\title{
Espessura crustal da transição dos domínios Província Tocantins - Bacia do Parnaíba: uma aproximação por função do receptor
}

Cássia Luisa Oliveira Peixoto ${ }^{1}$; Fábio Augusto S. Rocha ${ }^{1}$; Cíntia Rocha da Trindade ${ }^{1}$; José Eduardo P. Soares ${ }^{1}$; Reinhardt A. Fuck $^{1}$

${ }^{1}$ Laboratório de Estudos da Litosfera (LabLitos), Instituto de Geociências, Universidade de Brasília - UnB

Copyright 2012, SBGf - Sociedade Brasileira de Geofísica

Este texto foi preparado para a apresentação no V Simpósio Brasileiro de Geofísica Salvador, 27 a 29 de novembro de 2012. Seu conteúdo foi revisado pelo Comitê Técnico do V SimBGf, mas não necessariamente representa a opinião da SBGf ou de seus associados. É proibida a reprodução total ou parcial deste material para propósitos comerciais sem prévia autorização da SBGf.

\section{Abstract}

With about $2,000 \mathrm{~km}$ long and $800 \mathrm{~km}$ wide, the Tocantins Province is a region generated by the collision of the São Francisco and the Amazônico cratons in the Neoproterozoic. Northwards it is limited by the Parnaíba Basin. This work characterizes the transition between the Amazon Plate-Tocantins Province-Parnaíba Basin applying receiver function techniques to a network broadband stations working in central Brazil.

\section{Introdução}

A Província Tocantins, situada no Brasil central, corresponde a um sistema orogênico neoproterozóico de direção geral norte-sul contido entre os crátons São Francisco, a leste, e Amazônico, a oeste. Seus limites norte-sul são encobertos por rochas da Bacia do Parnaíba, a norte, e da Bacia do Paraná, a sul. Ela é composta por três faixas orogênicas de evolução diacrônica e diferentes trends estruturais: as faixas Araguaia e Paraguaia, bordejando o Cráton Amazônico, e a Faixa Brasília, a oeste do Cráton São Francisco (Almeida et al., 1977).

A Faixa Brasília é constituída por duas porções de diferentes trends estruturais: a porção setentrional, de orientação geral NE, e a porção meridional, de orientação geral SW

A Bacia do Parnaíba é uma bacia intracratônica paleozóica compartimentada principalmente pelas estruturas geradas durante o Ciclo Brasiliano, sendo que ao seu término, por subsidência termomecânica, os grabens foram preenchidos pelo progressivo afundamento ao longo das faixas tectonicamente instáveis.

Com a finalidade de determinar o comportamento crustal da região de transição entre esses dois domínios, o Laboratório de Estudos da Litosfera do IG UnB instalou estações sismográficas de banda larga região (Figura 1). Os dados sismológicos foram coletados por um período de três anos para as estações mais antigas e de um ano para as estações mais recentes. Esses dados foram utilizados para gerar sismogramas de Função do Receptor e assim esboçar a estrutura da crosta nos limites norte e oeste da Província Tocantins.

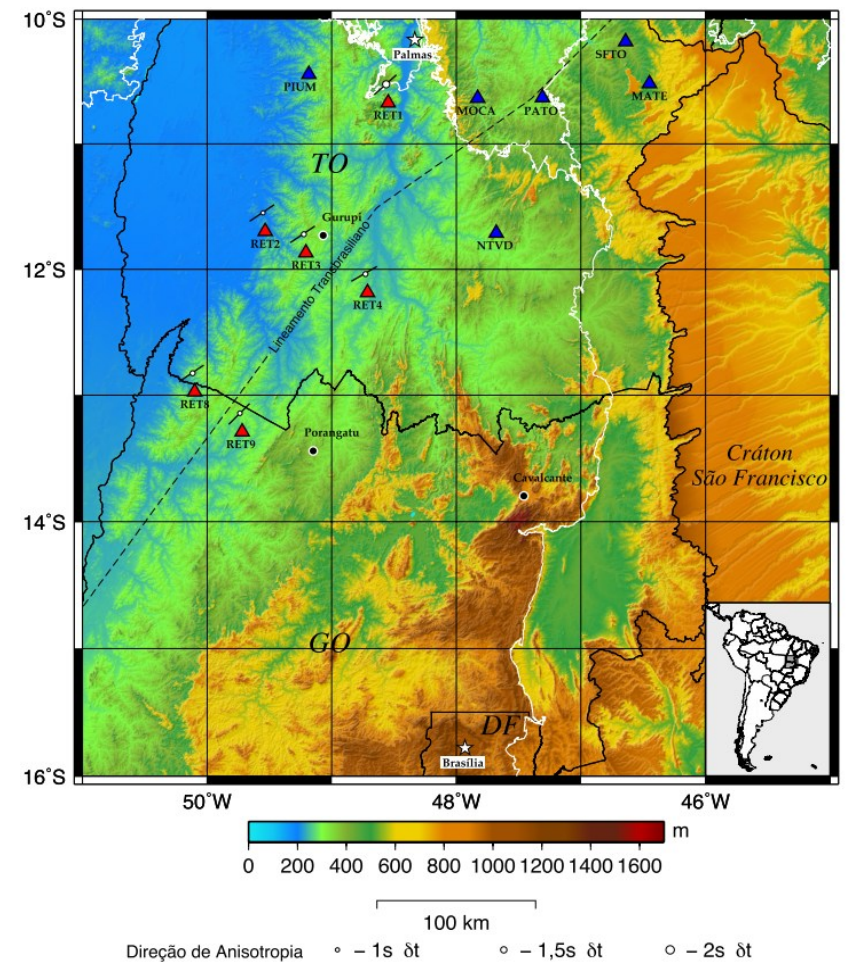

Figura 1 - Mapa topográfico com localização das estações.

\section{Metodologia}

Função do Receptor é uma técnica que utiliza registros telessísmicos com epicentros distando entre $30^{\circ}$ a $90^{\circ}$ da estação de três componentes para calcular espessura e razão de Poisson $\left(\mathrm{V}_{\mathrm{p}} / \mathrm{V}_{\mathrm{s}}\right)$ da crosta sob a mesma.A função do receptor obtém informações a partir do tempo de chegada de fase $P_{\mathrm{s}}$ e das múltiplas, $\left(\mathrm{P}_{\mathrm{p}} \mathrm{P}_{\mathrm{ms}}, \mathrm{P}_{\mathrm{p}} \mathrm{S}_{\mathrm{ms}}+\right.$ $\mathrm{P}_{\mathrm{s}} \mathrm{P}_{\mathrm{ms}}$ ) geradas por parte da energia da onda $\mathrm{P}$ de telessísmos incidentes na descontinuidade de Moho sob a estação. As frentes de onda incidem próximas à vertical abaixo de uma estação, que registra a onda $P$ dominante na componente vertical do registro, e a onda convertida em $S$ predominante na componente radial. As fases Ps e suas múltiplas são obtidas deconvolvendo a componente vertical de registro da componente radial. Deconvolvendo a componente vertical da componente radial é possível isolar a estrutura da Terra sob a estação em forma de uma série temporal. Por meio do tempo de chegada dessas fases, e com o valor da $V_{p}$ média na crosta 
calculamos profundidade da descontinuidade e razão $\mathrm{V}_{\mathrm{p}} / \mathrm{V}_{\mathrm{s}}$ a partir das relações abaixo:

$$
\begin{gathered}
\frac{V_{P}}{V_{S}}=\left\{\left(1-p^{2} V_{P}^{2}\right)\left[2\left(\frac{t_{P_{S}}-t_{P}}{t_{P p P m s}-t_{P_{S}}}\right)+1\right]^{2}+p^{2} V_{P}^{2}\right\}^{1 / 2} . \\
H=\frac{V_{P}\left(t_{P_{S}}-t_{P}\right)}{\left(\sqrt{\frac{V_{P}^{2}}{V_{S}^{2}}-p^{2} V_{P}^{2}}-\sqrt{1-p^{2} V_{P}^{2}}\right)},
\end{gathered}
$$

Onde $\mathrm{p}$ é o parâmetro de raio, $\mathrm{H}$ é espessura da crosta $\mathrm{e}$ té o tempo de chegada das fases.

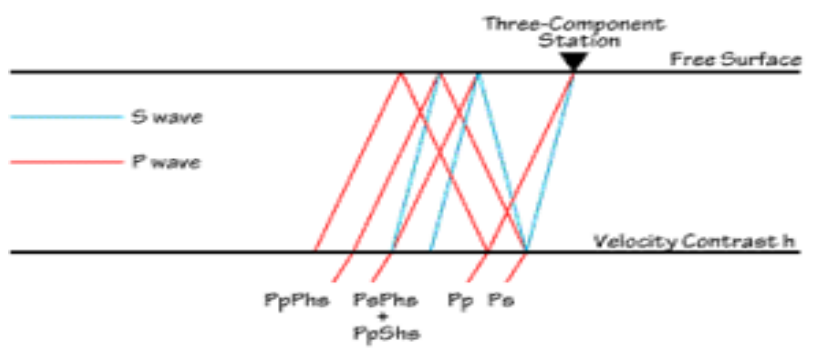

Figura 2 - Esboço de frente de onda plana incidindo na base da crosta e gerando ondas $P$ e $S$ diretas e $S$ múltiplas.

Foram utilizados eventos com magnitude igual ou superior a $6.0\left(m_{b}\right.$ e $\left.M_{s}\right)$ e parâmetro de raio entre 4.6 $8.9 \mathrm{rad} / \mathrm{km} / \mathrm{s}$. Os sismogramas de função do receptor foram obtidos por deconvolução no domínio da frequência utilizando o programa pwaveqn (Ammon, 1997). Os sinais de função do receptor com parâmetros de raio próximos (independentes do azimute) apresentaram $P_{s}$ similar e foram estaqueados gerando um único traço. A espessura e razão de Poisson sob cada estação foram obtidas com o programa Hk-stack.

As estações com localização dentro da Bacia do Parnaíba apresentaram razão sinal-ruído muito abaixo dos registros das estações situadas fora da Bacia.

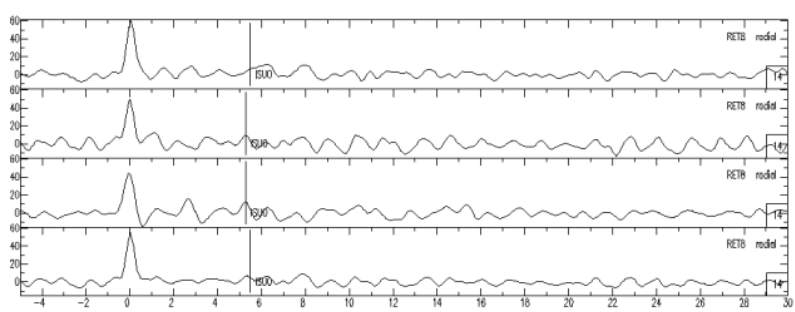

Figura 3 - Exemplo de resultados de função do receptor da estação RET8

\section{Resultados}

Foram obtidos valores de espessura e $V_{p} / V_{s}$ para a crosta em toda a região analisada. A Tabela 1 mostra que os valores da crosta variam de 35 a $40 \mathrm{~km}$ para o domínio da Bacia do Parnaíba, e de 41 a $52 \mathrm{~km}$ para a
Província Tocantins, refletindo a complexidade estrutural da área.

\begin{tabular}{|c|c|c|c|c|c|}
\hline ESTACÕES & $\begin{array}{c}\text { Coordenadas } \\
\text { Lat.( }\left(^{\circ}\right) / \text { Long. }\left(^{\circ}\right)\end{array}$ & $\mathbf{V p} / \mathbf{N}$ & $\mathbf{V p}(\mathbf{K m} / \mathbf{s})$ & $\mathbf{H}(\mathbf{K m})$ & Localização \\
\hline RET1 & $-10.7 /-48.6$ & 1.72 & 6.3 & 42.5 & Porto Nacional-TO \\
\hline RET2 & $-11.7 /-49.5$ & $1.79 / 1.76$ & $6.3 / 6.7$ & $42.8 / 46.3$ & Formoso do Araguaia-TO \\
\hline RET3 & $-11.9 /-49.2$ & $1.74 / 1.71$ & $6.3 / 6.7$ & $44.5 / 48.4$ & Cariri-TO \\
\hline RET4 & $-12.2 /-48.7$ & $1.72 / 1.70$ & $6.3 / 6.7$ & $40.4 / 43.5$ & Sucupira-TO \\
\hline RET8 & $-13.0 /-50.1$ & $1.79 / 1.77$ & $6.3 / 6.7$ & $39.0 / 42.6$ & São Miguel do Araguaia-GO \\
\hline RET9 & $-13.29 /-49.72$ & 1.74 & 6.7 & 52.4 & Novo Planalto-GO \\
\hline SFTO & $-10.18238 /-46.64194$ & $1.76 / 1.70$ & 6.4 & $36.2 / 40.7$ & São Felix do Tocantins-TO \\
\hline PATO & $-10.62929 /-47.3084$ & 1.75 & 6.4 & 34.8 & Ponte Alta do Tocantins-TO \\
\hline MATE & $-10.51607 /-46.44958$ & 1.77 & 6.4 & 39.9 & Mateiros-TO \\
\hline PIUM & $-10.4432 /-49.1823$ & $1.86 / 1.74$ & 6.4 & $49.6 / 52.1$ & Pium-TO \\
\hline
\end{tabular}

Tabela 1: Valores de velocidade, espessura sob as estações e suas localizações.

A Figura 4 apresenta os resultados da inversão utilizando o programa Hk-satck (onde a espessura é obtida em função da razão de Poisson) para as quatro estações de instalação mais recente, MATE, PIUM, SFTO e PATO.

Esses resultados ainda são preliminares e serão melhorados a medida que for aumentando o banco de dados.

A estação PIUM mostra ambiguidade nos resultados, mas apresenta crosta anormalmente espessa com valores em torno de $50 \mathrm{~km}$.
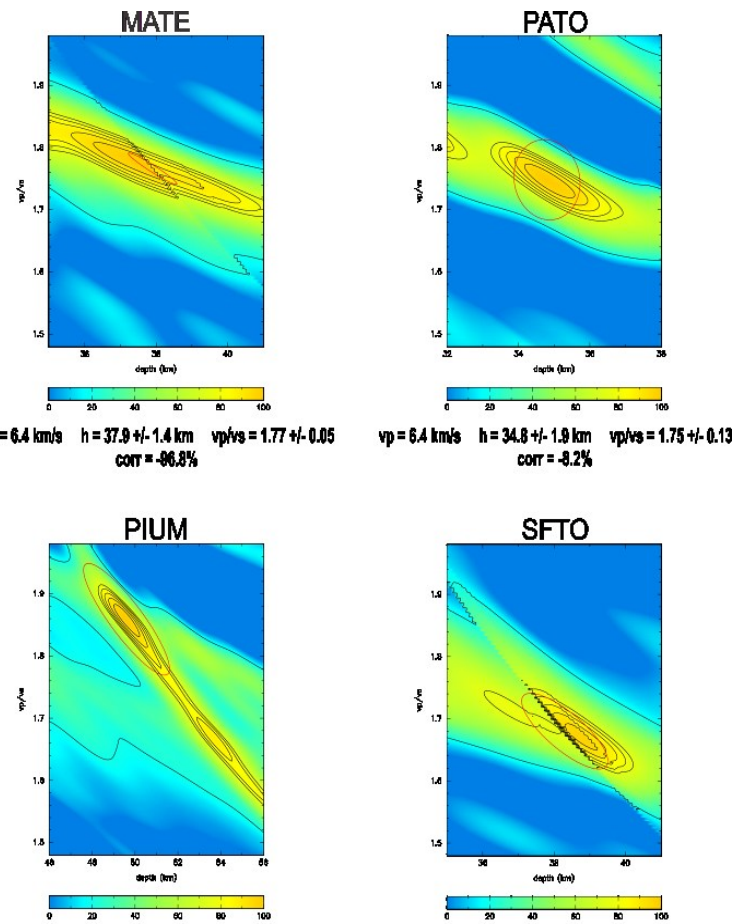

$v p=6.4 \mathrm{~km} / \mathrm{s} \quad h=49.8+1.4 .0 \mathrm{kmm} \quad \mathrm{pphs}=1.86+1.0 .18$ cor $=28.3 \%$

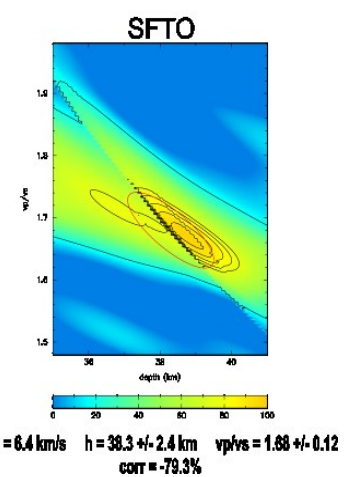

Figura 4 - Empilhamento dos dados

\section{Discussão e Conclusões}

A região limite entre a Província Tocantins e a placa Amazônica passa pelas estações RET9, RET3 e PIUM, região marcada por forte gradiente gravimétrico Bouguer 
(Figura 5). Ao longo do gradiente Bouguer a crosta é caracterizada por razão $V_{p} / V_{s}$ de 1,74 e espessura acima da média (48 a $52 \mathrm{~km}$ ) sugerindo superposição de crosta inferior.

A Placa Amazônica, domínio da Faixa Araguaia, é marcada por $V_{\mathrm{p}} / \mathrm{V}_{\mathrm{s}}$ de 1,78 e espessuras em torno de 40 km (RET2 e RET8).

A estação RET4 apresenta razão $V_{p} / V_{s}$ de 1,72 e espessura de $40 \mathrm{~km}$ caracterizando o arco magmático de Goiás. Valores coerentes com resultados obtidos anteriormente para o arco magmático de Goiás na região de Porangatú.

A Bacia do Parnaíba é caracterizada por $V_{p} / V_{s}$ em torno de 1.76 espessura crustal em torno de $35 \mathrm{~km}$ apresentando uma descontinuidade em direção a MATE onde a crosta sofre espessamento para $40 \mathrm{~km}$.

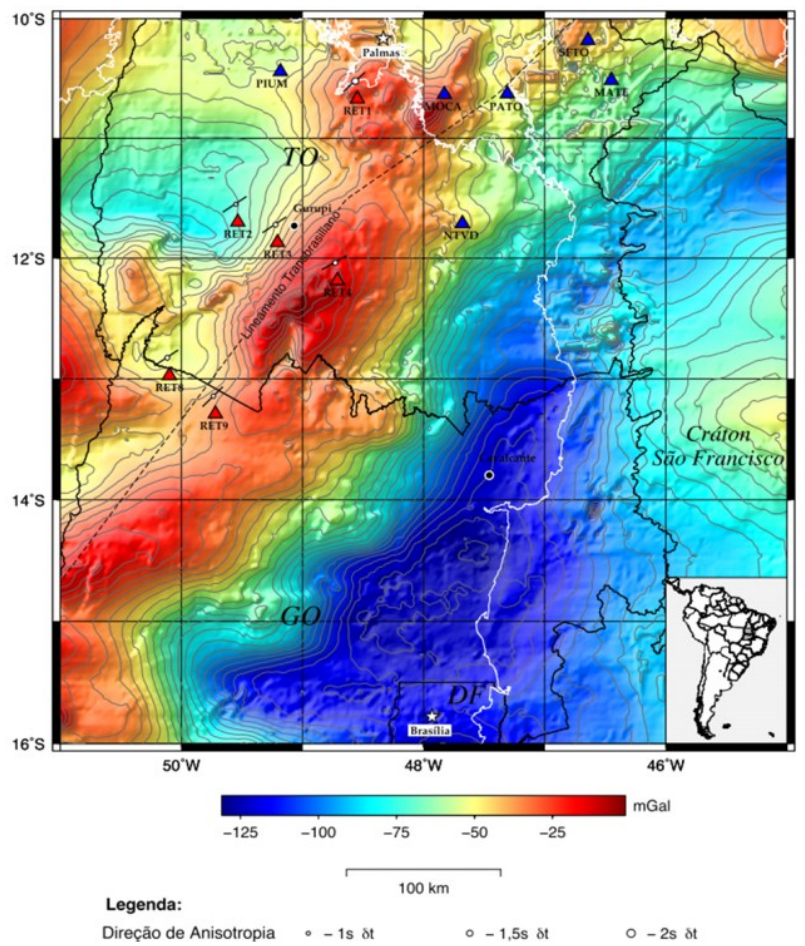

Figura 5 - Mapa de anomalia Bouguer com as estações.

A Figura 6 apresenta os resultados acima na forma de perfis esboçando a estrutura crustal enfatizando as variações abruptas de espessura, que na maioria das vezes marcam limites geológicos.

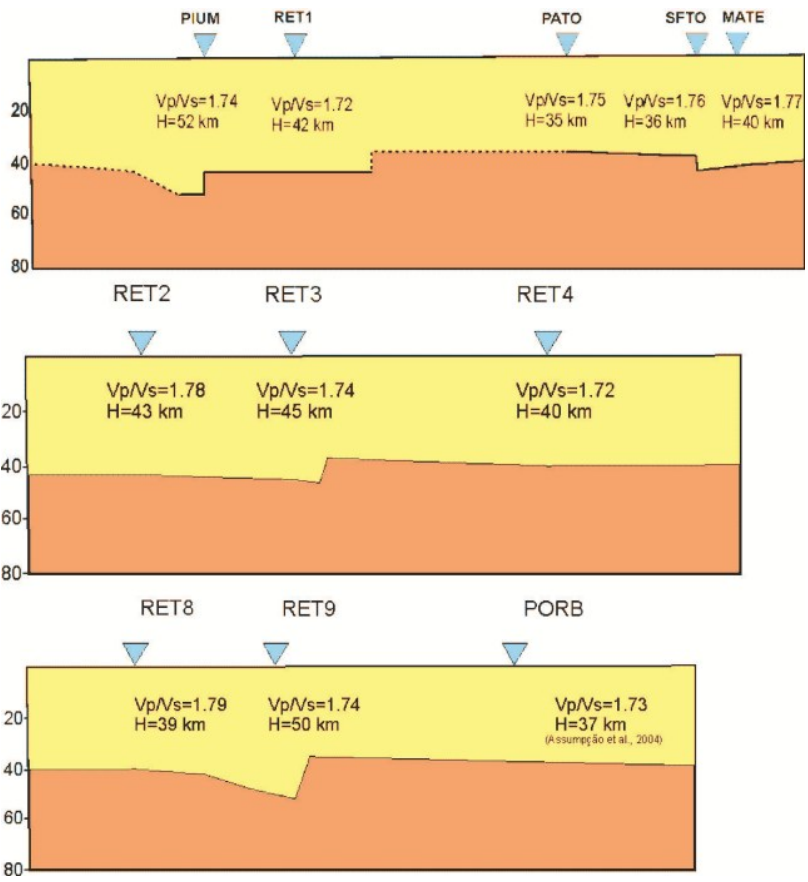

Figura 6 - Perfis com espessura e $V_{p} / V_{s}$ da crosta do Brasil Central obtidos a partir das estações sismográficas apresentadas no mapa de anomalia Bouguer da figura 5.

\section{Agradecimentos}

Ao Laboratório de Estudos da Litosfera- UnB por ter cedido os dados e materiais para o desenvolvimento dessa pesquisa.

Ao professor Dr. José Eduardo Pereira Soares por ter orientado e incentivado os estudos sobre estrutura crustal.

\section{Referências}

Ammon, C.J., 1997. An overview of receiver function analysis. Citação de referências e documentos eletrônicos. Disponível em: http://www.essc.psu.edu/ ammom/HTML/RftnDocs/rftn01 .html.

Almeida, F. F. M., Hasui, Y., Brito Neves, B.B., Fuck, R.A. 1977. Províncias Estruturais Brasileiras. In: SBG/Núcleo Nordeste, 8 Simp. Geol. Nordeste, Campina Grande (PB), Boletim, 6: $363-391$.

Zandt G. \& Ammon C.J. 1995. Continental crust composition constrained by measurements of crustal Poisson's ratio. Nature, 374:152-154. 